\title{
Optic nerve head analyser and Heidelberg retina tomograph: accuracy and reproducibility of topographic measurements in a model eye and in volunteers
}

Peter Janknecht, Jens Funk

\begin{abstract}
The accuracy and reproducibility of the optic nerve head analyser (ONHA) and the Heidelberg retina tomograph (HRT) were compared and the performance of the HRT in measuring fundus elevations was evaluated. The coefficient of variation of three repeated measurements in a model eye and in volunteers and the relative error in a model eye was calculated. With ONHA measurements the pooled coefficient of variation in volunteers was $9.3 \%$ in measuring cup areas and $8.4 \%$ in measuring the cup volume. In a model eye the pooled coefficient of variation was $7 \cdot 6 \%$ for the parameter 'cup area' and $\mathbf{9 . 9 \%}$ for the parameter 'cup volume'. The pooled relative error in the model eye was $6.6 \%$ for the parameter 'cup area' and $5.1 \%$ for the parameter 'cup volume'. With HRT measurements in volunteers the pooled coefficient of variation of both the parameters 'volume below contour' and 'volume below surface' was $6.9 \%$. In the model eye the pooled coefficient of variation was $2.4 \%$ for the 'volume below contour' and $4.1 \%$ for the parameter 'volume below surface'. The pooled relative error in the model eye was $11.3 \%$ for the 'volume below contour' and $11 \%$ for the 'volume below surface'. The pooled relative error in measuring retinal elevations in the model eye was $3 \cdot 8 \%$. The coefficient of variation was $3.5 \%$. The accuracies of the HRT and ONHA were similar. However, as the ONHA 'cup volume' is unreliable in patients because of the design of the ONHA whereas the HRT volume parameters are reliable it seems reasonable to assume that the HRT is superior to the ONHA. Only the HRT is capable of quantifying retinal elevations.
\end{abstract} (BrF Ophthalmol 1994; 78: 760-768)

A reliable method for the detection of early and progressive optic nerve head damage is essential in the monitoring and treatment of patients with glaucoma. Until recently, the reproducibility and accuracy of automatic analysis of the optic disc were not completely satisfying. ${ }^{1-7}$ The latest instrument for the topographic analysis of the papilla is the Heidelberg retina tomograph (HRT). We wanted to compare the accuracy and reproducibility of the HRT with the optic nerve head analyser (ONHA). Both the ONHA and the HRT provide automatic quantitative measurements of the papilla. There are reports about the reproducibility of the ONHA, ${ }^{12457}$ the HRT, ${ }^{8}$ and the predecessor of the HRT, the laser scanning tomograph. ${ }^{9-11}$ Neither of these studies, however, compare the reproducibility of the ONHA to the reproducibility of the HRT. Reports about the accuracy of the HRT are still missing.

The HRT is capable of measuring fundus elevations such as naevi or macular oedema. Data about the accuracy and reproducibility of the HRT in measuring elevations are still missing. We provide such data and furthermore determined and compared the reproducibility of the ONHA and the HRT in a model eye and in volunteers and calculated their relative error using a model eye.

\section{Materials and methods}

INSTRUMENTATION

We used the ONHA of Rodenstock Instruments, Germany with updated software ('ONHA plus'). Details of the instrument have been published elsewhere. ${ }^{12} 13$ The ONHA records stereoscopic video images after projecting a set of stripes on the papilla. The displacement of the stripes permits the calculation of a contour map of the surface of the disc area. The operator selects four cardinal locations of the disc margin which is projected onto the computer monitor, and the computer calculates an ellipse as the disc margin. The plane which is $150 \mu \mathrm{m}$ below the reference plane of the disc margin is defined as the 'cup area'. The rim area is the difference between the total disc area and the cup area. The 'cup volume' specifies the volume beneath a retinal reference plane. The latter is defined by the average topography of the peripapillary area.

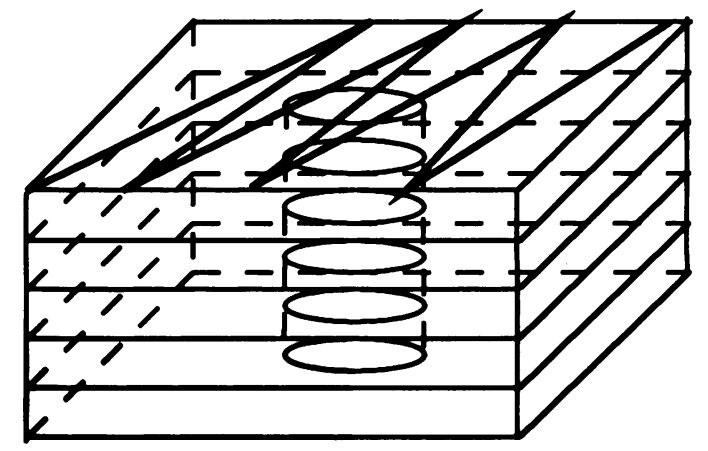

Figure 1 Diagram showing six of 32 stacked focal planes which are scanned one after the other (scan line indicated by thick black line on the uppermost plane) by the Heidelberg retina tomograph. The accumulated data permit the calculation of a three dimensional image of the papilla. 


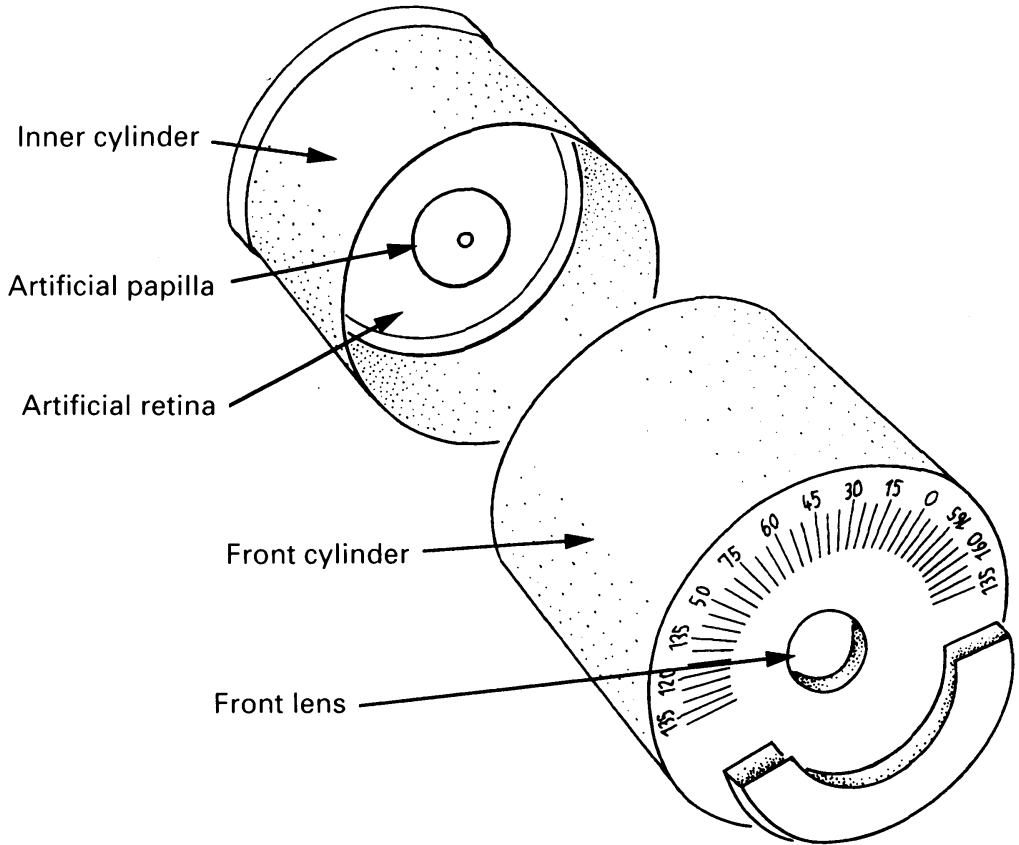

Figure 2 Model eye. The model eye consisted of two cylinders. The smaller cylinder (on the left ) could slide into the larger one and consisted of an orange artificial retina with a hole into which artificial papillae could be inserted. The larger cylinder was equipped with a $+20 \mathrm{D}$ lens.

We took the HRT of Heidelberg Engineering, Germany for comparison with the ONHA. The HRT is an updated version of the former laser scanning tomograph (Heidelberg Instruments, Germany). Details of the HRT confocal image acquisition and processing have been described elsewhere. ${ }^{10}$ The confocal optical system permits detection of light that is reflected from a very thin optical plane, the focal plane, whereas it suppresses light that is scattered or deflected from outside the optical plane. By moving the focus posteriorly the camera of the HRT registers 32 stacked focal planes (Fig 1) and the computer calculates a three dimensional image of the papilla. Each of the 32 focal planes is scanned by means of a system of mirrors which deflects the laser beam and at the same time permits incoming light to reach a detector. The HRT places one of the focal planes, the main focal plane, on the retina. The main focal plane is a reference plane that is defined to have zero height. Elevations and depressions of the fundus are related to this reference plane.

A colour coded topographic map that is projected on the computer screen permits the operator to draw a contour line around the disc. The mean height of the contour line with regard to the main focal plane is calculated. The 'volume below contour' is the volume below a reference plane that is perpendicular to the optical axis at a height location that equals the mean height of the contour line. An irregular surface the boundary of which possesses the height of the contour line, and the centre of which has the mean height of the contour line, is chosen as a reference plane for the calculation of the parameter 'volume below surface' and 'volume above surface'. We used both parameters in our study. The computer constructs a plane which is perpendicular to the main focal plane and runs through a point which has the mean height of the contour line for the calculation of the 'volume below contour'. The volume below this plane is the 'volume below contour'.
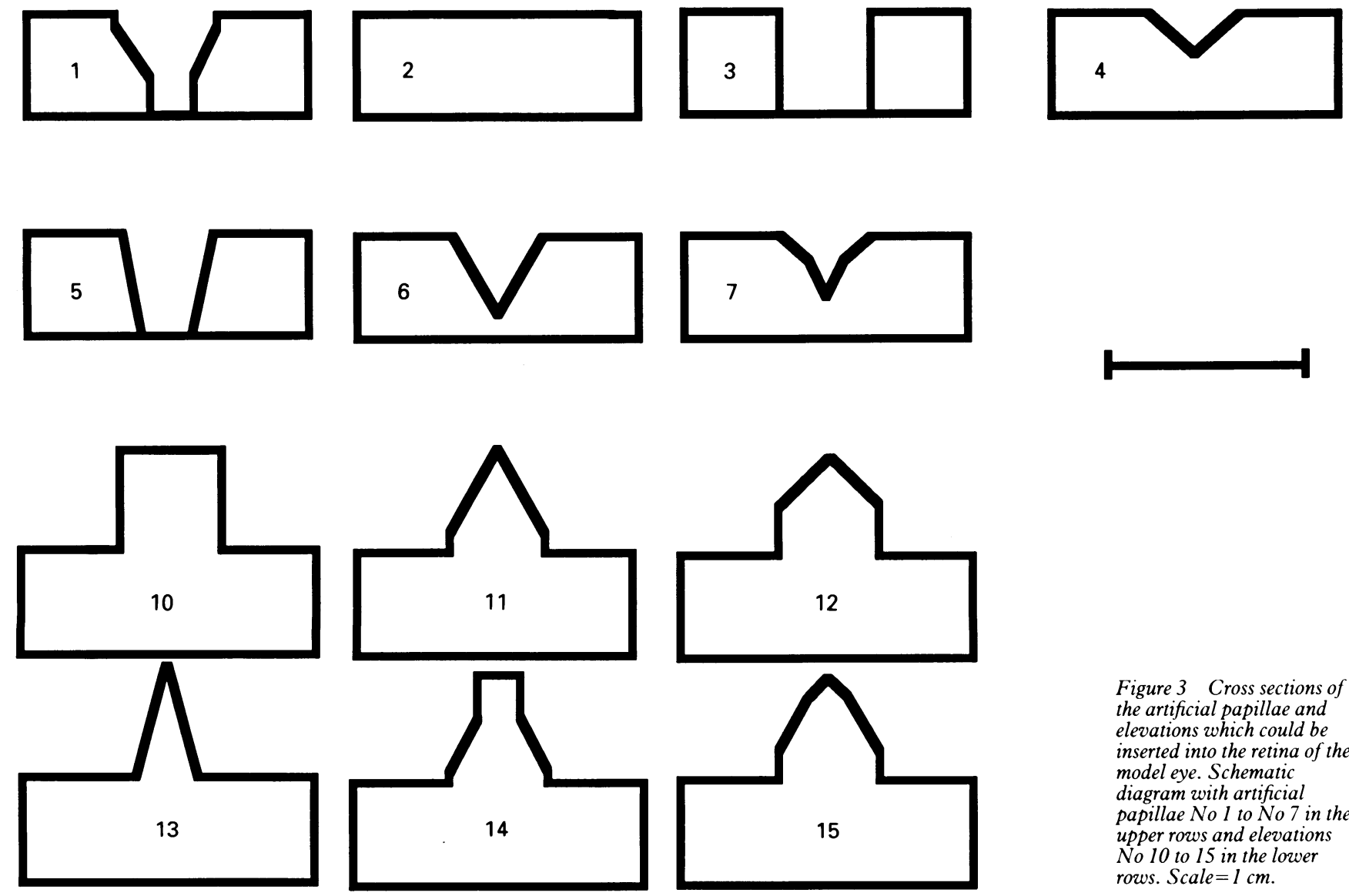

Figure 3 Cross sections of the artificial papillae and
elevations which could be inserted into the retina of the model eye. Schematic diagram with artificial papillae No 1 to No 7 in the upper rows and elevations No 10 to 15 in the lower rows. Scale $=1 \mathrm{~cm}$. 
MODEL EYE

We constructed a model eye (Fig 2) for evaluation of the accuracy of the ONHA and the HRT. Two cylinders were fashioned so that the one of them could slide into the other. The inner curved surface (artificial retina) of the smaller cylinder possessed a hole for the insertion of various buttons (artificial papillae) with depressions of known size and shape or elevations of known geometry (Fig 3: cross sections of the artificial papillae and of the elevations). The larger cylinder had a $+20 \mathrm{D}$ lens glued into a front hole. The inner cylinder was slit into the larger one so that the artificial retina was $50 \mathrm{~mm}$ away from the lens. The inner surfaces of the model eye were black with the exception of the artificial retina which was orange. The model eye was air filled. There were six artificial papillae, a cylinder, several cones, and a combination of a cone and a cylinder (Fig 3), and six elevations (cylinders, cones, and combinations of cylinders and cones, Fig - 3). Furthermore, a flat button was used to find out whether cup areas or volumes that do not exist were mistakenly recorded by the ONHA or HRT.

The optical data of the model eye did not equal those of the Gullstrand model eye which is programmed into the ONHA and the HRT. Therefore, the data of the model eye had to be adjusted by magnification factors that were derived from theoretical optical calculations. ${ }^{13}$ Briefly, the following calculations were done: the visual angle of Gullstrand's normal eye was divided by the visual angle of our model eye yielding a factor $\mathrm{k}$. Factor $\mathrm{k}$ was 2.9 for ONHA and HRT measurements of the artificial papillae. The real volumes of our artificial papillae were divided by the fourth power ${ }^{13}$ of $k$ to adjust them to Gullstrand's normal eye and to be able to compare them with the measured values. The real sectional areas of our artificial papillae were adjusted by dividing them ${ }^{13}$ by the square of $k$ to adjust it to Gullstrand's normal eye.

\section{VOLUNTEERS}

There were 15 volunteers (six men, nine women) with a mean age of 28 years and no known history of glaucoma or any eye diseases. The pupils were dilated to more than $5 \mathrm{~mm}$ diameter by tropicamide for measurements with the ONHA and HRT.

\section{STUDY DESIGN}

The model eye was mounted on the chin rest of the ONHA. Each of the artificial papillae and elevations and the flat button was measured three times - that is, three image acquisitions were performed. Between every measurement we moved the model eye so that a position different from the former analysis was found. Each of the three acquired image series was analysed separately and the parameters 'cup area' and 'cup volume' were taken for further analysis. Measurements and data analysis were done by one of us (PJ).

The same model eye was mounted on the chin rest of the HRT: $10^{\circ}\left(20^{\circ}\right.$ for elevations) scans were taken, the scan depth varied according to the type of artificial cup and ranged between 1.5 and $2.5 \mathrm{~mm}$. Plus lenses were inserted in front of the camera of the HRT to shift the focal plane in a manner that all the artificial papillae could be measured without having to use too large a scan range. The elevations were recorded with $\mathrm{a}+2 \cdot 5$ or $+3.5 \mathrm{D}$ lens in front of the camera of the HRT to shift the main focal plane into the 'vitreous' of the model eye so that all parts of the elevations could be recorded. Each of the six artificial cups and six elevations and the flat button was measured three times - that is, three image acquisitions were performed. Between every measurement we moved the model eye so that a position different from the former analysis was found. Each of the three image series was analysed once and the parameters 'volume below contour' and 'volume below surface' were taken for further analysis. For the analysis of the elevations the parameter 'volume above surface' was used. Measurements and data analysis were done by one of us (PJ).

The volunteers were analysed three times each with both the ONHA and the HRT. The papilla was examined. There were three image series per patient with each of the two instruments. Every image series was analysed separately and the parameters 'cup area' and 'cup volume' (ONHA) and 'volume below contour (surface)' and 'volume above surface' (HRT) were used for further analysis. Measurements and data analysis were done by one of us (PJ).

\section{STATISTICS}

We calculated the mean value and standard deviation of three repeated measurements.

The relative error was defined as:

$$
\text { relative error }=\frac{\text { mean of the measured values }}{\text { actual value }} \times 100-100 \%
$$

*after correction for dimensions (Gullstrand data)

The definition of the relative error was the same as the one used by Dreher..$^{14}$ As we wanted to calculate the pooled relative error of the measurements of the various artificial papillae and elevations we decided to use the absolute values of the relative error - that is, pooled relative error $=1 / n \star \Sigma$ abs (relative error), where $\mathrm{n}=$ number of artificial papillae or elevations, respectively. The pooled relative error has the advantage of being one single parameter for the description of the performance of the ONHA or HRT, respectively. Its disadvantages (the disguise of the range of the relative errors and of outliers) are overcome by always noting the pooled relative errors and their range.

The coefficient of variation was defined as:

$$
=\frac{\text { standard deviation of the measured values }}{\text { mean of the measured values }}
$$

We used the coefficient of variation as a measure of reproducibility. The coefficient of variation is calculated with the mean value of the repeated measurements in the denominator. So, the smaller the mean values are, the smaller the denominator and the higher the coefficient of variation is. Although we know about the problems of using the coefficient of variation as means of quantifying the reproducibility we neverthe- 


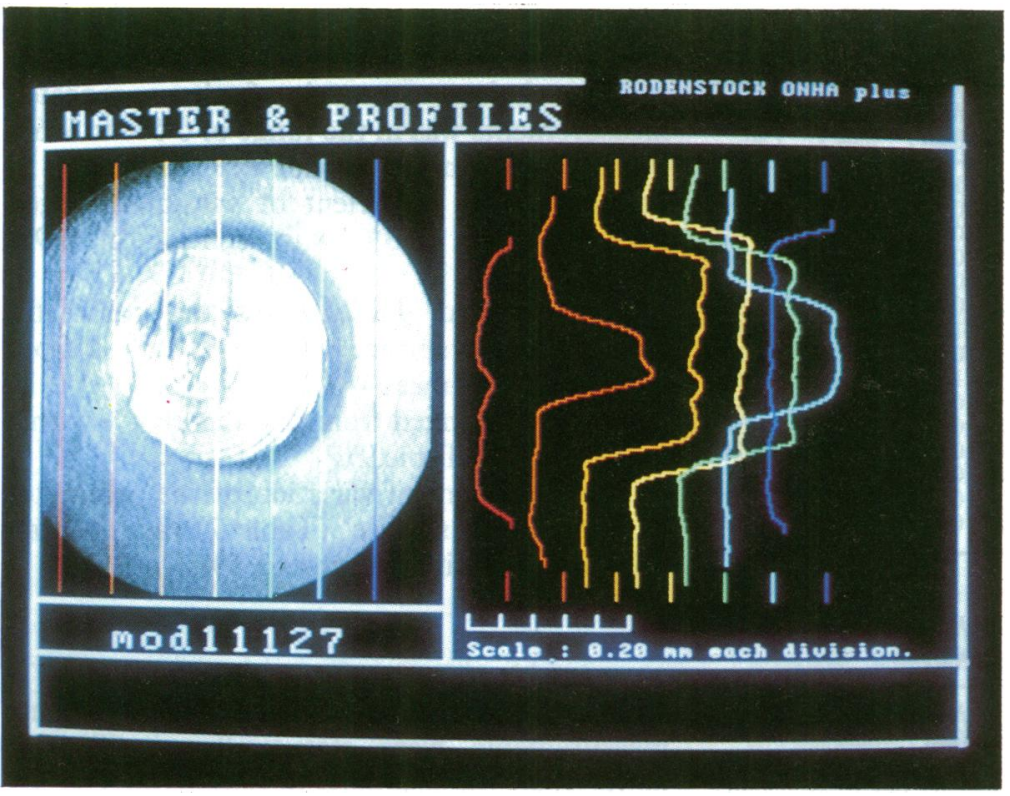

Figure 4 Optic nerve head analyser computer monitor displaying a topographic map of a cylindrical artificial papilla.

less used it for two reasons. Firstly, it is a straightforward parameter. Secondly, we used it to be able to compare our results to other investigators.

The relative errors and standard deviations of ONHA and HRT were compared by using the Wilcoxon signed rank test. As there are no reports about the distribution of cup area and cup volume data it seems appropriate to use a non-parametric statistical test such as the Wilcoxon signed rank test. There is, of course, some loss of information but this is more acceptable than using statistical tests which are based on assumptions that have not yet been verified (such as a normal distribution).

Table 1 Repeated measurements of the cup area of artificial papillae types 1 to 7 using the optic nerve head analyser

\begin{tabular}{|c|c|c|c|c|c|c|c|c|}
\hline No & $\begin{array}{l}\text { Cup area } \\
\left(m^{2}\right)\end{array}$ & & & $\begin{array}{l}\text { Mean } \\
\left(m m^{2}\right)\end{array}$ & $\underset{\left(\mathrm{mm}^{2}\right)}{\text { Real }}$ & $\begin{array}{l}S D \\
\left(m m^{2}\right)\end{array}$ & $\begin{array}{l}C V \\
(\%)\end{array}$ & $\begin{array}{l}\text { Relative } \\
\text { error }(\%)\end{array}$ \\
\hline $\begin{array}{l}1 \\
2 \\
3 \\
4 \\
5 \\
6 \\
7\end{array}$ & $\begin{array}{l}1 \cdot 257 \\
0 \\
2 \cdot 237 \\
0.466 \\
1 \cdot 157 \\
1.601 \\
0.435\end{array}$ & $\begin{array}{l}1 \cdot 288 \\
0 \\
2 \cdot 249 \\
0.682 \\
1.095 \\
1.653 \\
0.552\end{array}$ & $\begin{array}{l}1 \cdot 281 \\
0 \\
2 \cdot 196 \\
0 \cdot 448 \\
1 \cdot 067 \\
1 \cdot 583 \\
0 \cdot 493\end{array}$ & $\begin{array}{l}1.275 \\
0 \\
2 \cdot 227 \\
0.532 \\
1.106 \\
1.612 \\
0.493\end{array}$ & $\begin{array}{l}1 \cdot 54 \\
0 \\
2 \cdot 33 \\
0 \cdot 57 \\
1 \cdot 14 \\
1 \cdot 71 \\
0.45\end{array}$ & $\begin{array}{l}0.016 \\
0 \\
0.028 \\
0.13 \\
0.046 \\
0.036 \\
0.059\end{array}$ & $\begin{array}{c}1 \cdot 275 \\
\star \\
1 \cdot 248 \\
24 \cdot 48 \\
4 \cdot 163 \\
2 \cdot 255 \\
11 \cdot 86\end{array}$ & $\begin{array}{c}-17 \cdot 19 \\
0 \\
-4 \cdot 41 \\
-6 \cdot 67 \\
-2.95 \\
-5 \cdot 71 \\
9 \cdot 39\end{array}$ \\
\hline
\end{tabular}

$\mathrm{CV}=$ coefficient of variation

^No value calculated because mathematically impossible.

†After adjusting to Gullstrand's normal eye.

Table 2 Repeated measurements of the cup volume of artificial papillae types 1 to 7 using the optic nerve head analyser

\begin{tabular}{|c|c|c|c|c|c|c|c|c|}
\hline \multirow[b]{2}{*}{$\begin{array}{l}\text { No } \\
1 \\
2 \\
3 \\
4 \\
5 \\
6 \\
7\end{array}$} & \multicolumn{3}{|c|}{$\begin{array}{l}\text { Cup volume } \\
\left(\mathrm{mm}^{3}\right)\end{array}$} & $\begin{array}{l}\begin{array}{l}\text { Mean } \\
\left(\mathrm{mm}^{3}\right)\end{array} \\
0.797\end{array}$ & $\begin{array}{l}\begin{array}{l}\text { Real } \\
\left(\mathrm{mm}^{3}\right)\end{array} \\
0.67\end{array}$ & $\begin{array}{l}\begin{array}{l}S D \\
\left(\mathrm{~mm}^{3}\right)\end{array} \\
0.033\end{array}$ & $\frac{\begin{array}{l}C V \\
(\%)\end{array}}{4.095}$ & $\begin{array}{c}\begin{array}{c}\text { Relative } \\
\text { error }(\%)\end{array} \\
19.0\end{array}$ \\
\hline & $\begin{array}{l}0.78 \\
0 \\
1.41 \\
0 \cdot 218 \\
0.432 \\
0 \cdot 707 \\
0 \cdot 139\end{array}$ & $\begin{array}{l}0 \cdot 777 \\
0 \\
1 \cdot 453 \\
0 \cdot 249 \\
0 \cdot 448 \\
0 \cdot 842 \\
0 \cdot 189\end{array}$ & $\begin{array}{l}0 \cdot 835 \\
0 \\
1 \cdot 37 \\
0 \cdot 215 \\
0 \cdot 322 \\
0 \cdot 876 \\
0 \cdot 181\end{array}$ & $\begin{array}{l}0.797 \\
0 \\
1.411 \\
0.227 \\
0.401 \\
0 \cdot 808 \\
0 \cdot 17\end{array}$ & $\begin{array}{l}0.67 \\
0 \\
1 \cdot 4 \\
0 \cdot 23 \\
0 \cdot 4 \\
0 \cdot 78 \\
0 \cdot 19\end{array}$ & $\begin{array}{l}0.033 \\
0 \\
0.042 \\
0.019 \\
0.069 \\
0.089 \\
0.027\end{array}$ & $\begin{array}{l}4 \cdot 095 \\
\star \\
2 \cdot 942 \\
8 \cdot 28 \\
17 \cdot 12 \\
11 \cdot 6 \\
15 \cdot 83\end{array}$ & $\begin{array}{c}19 \cdot 0 \\
0 \\
0.79 \\
-1 \cdot 16 \\
0 \cdot 17 \\
3.63 \\
-10.7\end{array}$ \\
\hline
\end{tabular}

$\mathrm{CV}=$ coefficient of variation.

^No value calculated because mathematically impossible.

†After adjusting to Gullstrand's normal eye.
Results

OPTIC NERVE HEAD ANALYSER

\section{Accuracy}

To get an impression of the accuracy of the ONHA, we looked at the topographic map of the artificial papillae as they were measured by the ONHA. Figure 4 shows the ONHA computer monitor displaying the topographic map of the artificial papilla No 3 (see also Fig 3). The No 3 artificial papilla was a cylinder. Cross sectional profiles through the cylinder at locations as indicated on the left side of the computer screen are plotted on the right side. The 'excavation' was correctly found to be cylindrical. The edges were not registered to be as sharp as they really were. There was not much electronic noise. Similar results were found in the other artificial papillae.

The accuracy was quantified comparing the measured cup area and cup volume with the real ones of the model eye. The ONHA values (Table 1) differed from the theoretical ones by $-17 \cdot 2$ to $9.4 \%$ (pooled relative error $6.6 \%$ ). The relative error of the parameter 'cup volume' ranged from -10.7 to $19 \%$ with a pooled relative error of $5 \cdot 1 \%$ (Table 2 ).

\section{Reproducibility}

The coefficient of variation of three repeated measurements of the parameter 'cup area' was in the range of $1 \cdot 3 \%$ to $24.5 \%$ (mean $7 \cdot 6 \%$ ) in the model eye (Table 1). The coefficient of variation of the parameter 'cup volume' ranged from $2.9 \%$ to $17 \cdot 1 \%$ (mean $9 \cdot 9 \%$, Table 2 ).

In volunteers the coefficient of variation of the 'cup area' ranged from $0 \cdot 075 \%$ to $39 \cdot 2 \%$ with a mean of $9.3 \%$ (Table 3 ). The coefficient of variation of the 'cup volume' ranged from $1.8 \%$ to $24.4 \%$ with a mean of $8 \cdot 4 \%$ (Table 4 ).

There were two outliers (Table 1 , artificial papilla No 4: $0.682 \mathrm{~mm}^{2}$; Table 3, patient No 8: $0.229 \mathrm{~mm}^{2}$ ). We decided, however, not to discard these outliers as doing so is always somewhat arbitrary.

\section{HEIDELBERG RETINA TOMOGRAPH}

\section{Accuracy}

Figure 5 displays the profiles of the artificial papillae and elevations along their horizontal axis as they were recorded by the HRT. The contours of the artificial papillae were scanned correctly. The edges were registered to be sharp. Their boundaries were registered to be straight lines without much electronic noise.

The relative error was quantified comparing the parameter 'volume below contour' ('volume below surface') as measured by the HRT with the theoretical value in the model eye. The HRT values of the volume below contour (Table 5) differed from the theoretical ones by -6.4 to $25.5 \%$ with a pooled relative error of $11 \cdot 3 \%$ (volume below surface: -9.9 to $25 \%$, pooled relative error $11 \cdot 0 \%$, Table 6 ).

The accuracy in measuring elevations ranged from $-9 \cdot 3$ to $2 \cdot 3$ with a pooled relative error of $3 \cdot 8 \%$ (Table 7 ). 
Table 3 Repeated measurements of the cup area in volunteers using the optic nerve head analyser

\begin{tabular}{|c|c|c|c|c|c|c|c|}
\hline No & $\begin{array}{l}\text { Age } \\
\text { (years) }\end{array}$ & $\begin{array}{l}\text { Cup are } \\
\left(\mathrm{mm}^{2}\right)\end{array}$ & & & $\begin{array}{l}\text { Mean } \\
\left(m^{2}\right)\end{array}$ & $\underset{\left(m m^{2}\right)}{S D}$ & $\begin{array}{l}C V \\
(\%)\end{array}$ \\
\hline 1 & 40 & 1.007 & $1 \cdot 223$ & & $\begin{array}{l}1 \cdot 125 \\
0.209\end{array}$ & $0 \cdot 1094$ & $\begin{array}{l}9.723 \\
0.050\end{array}$ \\
\hline 2 & 22 & $\begin{array}{l}0.357 \\
0.71\end{array}$ & $\begin{array}{l}0.436 \\
0.693\end{array}$ & $\begin{array}{l}0.404 \\
0.782\end{array}$ & $\begin{array}{l}0.399 \\
0.728\end{array}$ & $\begin{array}{l}0.0397 \\
0.0472\end{array}$ & $\begin{array}{l}9.959 \\
6.487\end{array}$ \\
\hline $\begin{array}{l}3 \\
4\end{array}$ & 22 & 0.446 & 0.376 & 0.397 & 0.406 & 0.0359 & 8.84 \\
\hline 5 & $\begin{array}{l}22 \\
22\end{array}$ & 0.462 & 0.375 & 0.42 & 0.419 & 0.0435 & 10.38 \\
\hline 6 & 32 & 0.709 & 0.682 & 0.712 & 0.701 & 0.0165 & $2 \cdot 357$ \\
\hline 7 & 30 & $1 \cdot 17$ & $1 \cdot 234$ & $1 \cdot 27$ & $1 \cdot 225$ & 0.0506 & $4 \cdot 136$ \\
\hline$o_{0}^{\prime}$ & 27 & 0.123 & 0.229 & 0.121 & 0.158 & 0.0618 & $39 \cdot 19$ \\
\hline 9 & 30 & $1 \cdot 271$ & 1.433 & 1.37 & $1 \cdot 358$ & 0.0817 & 6.014 \\
\hline 10 & 30 & 0.794 & 0.855 & 0.84 & 0.83 & 0.0318 & 3.831 \\
\hline 11 & 29 & 0.105 & $0 \cdot 167$ & $0 \cdot 128$ & 0.133 & 0.0313 & $23 \cdot 51$ \\
\hline 12 & 22 & 0.536 & 0.639 & 0.554 & 0.576 & 0.055 & 9.545 \\
\hline 12 & 20 & 0.769 & 0.768 & 0.768 & 0.768 & 0.0006 & 0.075 \\
\hline 14 & 3 & 0.563 & 0.59 & 0.59 & 0.582 & 0.0165 & 2.829 \\
\hline 15 & 26 & 0.448 & 0.465 & 0.44 & 0.453 & 0.0108 & $2 \cdot 383$ \\
\hline
\end{tabular}

$\mathrm{CV}=$ coefficient of variation

Table 4 Repeated measurements of the cup volume in volunteers using the optic nerve head analyser

\begin{tabular}{cllllllc}
\hline No & $\begin{array}{l}\text { Age } \\
\text { (years) })\end{array}$ & $\begin{array}{l}\text { Cup volume } \\
\left(\mathrm{mm}^{3}\right)\end{array}$ & & & $\begin{array}{l}\text { Mean } \\
\left(\mathrm{mm}^{3}\right)\end{array}$ & $\begin{array}{l}S D \\
\left(\mathrm{~mm}^{3}\right)\end{array}$ & $\begin{array}{l}\mathrm{CV} \\
(\%)\end{array}$ \\
\hline 1 & 40 & 0.589 & 0.63 & 0.69 & 0.636 & 0.0508 & 7.983 \\
2 & 22 & 0.229 & 0.304 & 0.218 & 0.25 & 0.0468 & 18.7 \\
3 & 25 & 0.383 & 0.369 & 0.481 & 0.411 & 0.061 & 14.85 \\
4 & 22 & 0.212 & 0.191 & 0.217 & 0.207 & 0.0138 & 6.676 \\
5 & 22 & 0.15 & 0.173 & 0.147 & 0.157 & 0.0142 & 9.079 \\
6 & 32 & 0.42 & 0.383 & 0.392 & 0.398 & 0.0193 & 4.844 \\
7 & 30 & 0.616 & 0.702 & 0.559 & 0.626 & 0.072 & 11.51 \\
8 & 27 & 0.135 & 0.148 & 0.143 & 0.142 & 0.0066 & 4.618 \\
9 & 30 & 0.9 & 0.997 & 0.973 & 0.957 & 0.0505 & 5.281 \\
10 & 30 & 0.317 & 0.341 & 0.331 & 0.33 & 0.0121 & 3.657 \\
11 & 29 & 0.105 & 0.071 & 0.117 & 0.098 & 0.0239 & 24.43 \\
12 & 22 & 0.228 & 0.236 & 0.234 & 0.233 & 0.0042 & 1.789 \\
13 & 30 & 0.534 & 0.53 & 0.556 & 0.54 & 0.014 & 2.593 \\
14 & 35 & 0.364 & 0.334 & 0.347 & 0.348 & 0.015 & 4.319 \\
15 & 26 & 0.179 & 0.199 & 0.201 & 0.193 & 0.0122 & 6.303 \\
\hline
\end{tabular}

Table 5 Repeated measurements of the volume below contour of artificial papillae types 1 to 7 using the Heidelberg retina tomograph

\begin{tabular}{|c|c|c|c|c|c|c|c|c|}
\hline No & \multicolumn{3}{|c|}{$\begin{array}{l}\text { Volume below contour } \\
\left(\mathrm{mm}^{3}\right)\end{array}$} & \multirow{2}{*}{$\begin{array}{c}\begin{array}{c}\text { Mean } \\
\left(\mathrm{mm}^{3}\right)\end{array} \\
0.627\end{array}$} & \multirow{2}{*}{$\begin{array}{c}\begin{array}{l}\text { Realt } \\
\left(\mathrm{mm}^{3}\right)\end{array} \\
0.67\end{array}$} & \multirow{2}{*}{$\begin{array}{l}\begin{array}{l}S D \\
\left(\mathrm{~mm}^{3}\right)\end{array} \\
0.017\end{array}$} & \multirow{2}{*}{$\begin{array}{l}\begin{array}{l}C V \\
(\%)\end{array} \\
2 \cdot 664\end{array}$} & \multirow{2}{*}{$\begin{array}{l}\begin{array}{l}\text { Relative } \\
\text { error }(\%)\end{array} \\
-6.4\end{array}$} \\
\hline 1 & 0.645 & 0.624 & 0.612 & & & & & \\
\hline 2 & 0.035 & 0.036 & 0.03 & 0.034 & & 0.003 & $9 \cdot 548$ & $\star$ \\
\hline 3 & 1.75 & 1.755 & 1.767 & 1.757 & 1.4 & 0.009 & 0.497 & $25 \cdot 5$ \\
\hline 4 & 0.225 & 0.226 & $0 \cdot 221$ & 0.224 & 0.23 & 0.003 & $1 \cdot 181$ & $-2 \cdot 6$ \\
\hline 5 & 0.413 & 0.408 & 0.41 & 0.41 & 0.4 & 0.003 & 0.613 & $2 \cdot 6$ \\
\hline 6 & 0.914 & 0.915 & 0.924 & 0.918 & 0.78 & 0.006 & 0.6 & $17 \cdot 7$ \\
\hline 7 & 0.218 & 0.215 & 0.212 & 0.215 & $0 \cdot 19$ & 0.003 & $1 \cdot 395$ & $13 \cdot 3$ \\
\hline
\end{tabular}

$\mathrm{CV}=$ coefficient of variation.

^No value calculated because mathematically impossible.

†After adjusting to Gullstrand's normal eye.

Table 6 Repeated measurements of the volume below surface of artificial papillae types 1 to 7 using the Heidelberg retina tomograph

\begin{tabular}{|c|c|c|c|c|c|c|c|c|}
\hline$\frac{N o}{1}$ & \multicolumn{3}{|c|}{$\begin{array}{l}\text { Volume below surface } \\
\left(\mathrm{mm}^{3}\right)\end{array}$} & $\frac{\begin{array}{c}\text { Mean } \\
\left(\mathrm{mm}^{3}\right)\end{array}}{0.604}$ & $\begin{array}{l}\begin{array}{l}\text { Real† } \\
\left(\mathrm{mm}^{3}\right)\end{array} \\
\begin{array}{l}0.67 \\
0\end{array}\end{array}$ & $\begin{array}{l}\begin{array}{l}S D \\
\left(\mathrm{~mm}^{3}\right)\end{array} \\
0.005 \\
0.005\end{array}$ & $\frac{\begin{array}{l}C V \\
(\%)\end{array}}{0.817}$ & $\begin{array}{c}\begin{array}{c}\text { Relative } \\
\text { error }(\%)\end{array} \\
-9.9\end{array}$ \\
\hline $\begin{array}{l}1 \\
2 \\
3 \\
4 \\
5 \\
6 \\
7\end{array}$ & $\begin{array}{l}0.606 \\
0.027 \\
1 \cdot 742 \\
0.211 \\
0.402 \\
0.911 \\
0.202\end{array}$ & $\begin{array}{l}0.607 \\
0.024 \\
1.746 \\
0.223 \\
0.402 \\
0.908 \\
0.206\end{array}$ & $\begin{array}{l}0.598 \\
0.017 \\
1 \cdot 76 \\
0.216 \\
0.405 \\
0.916 \\
0.205\end{array}$ & $\begin{array}{l}0.604 \\
0.023 \\
1.749 \\
0 \cdot 217 \\
0.403 \\
0.912 \\
0.204\end{array}$ & $\begin{array}{l}0 \cdot 67 \\
0 \\
1 \cdot 4 \\
0 \cdot 23 \\
0 \cdot 4 \\
0 \cdot 78 \\
0 \cdot 19\end{array}$ & $\begin{array}{l}0.005 \\
0.005 \\
0.009 \\
0.006 \\
0.002 \\
0.004 \\
0.002\end{array}$ & $\begin{array}{c}0 \cdot 817 \\
22 \cdot 64 \\
0.54 \\
2 \cdot 782 \\
0.43 \\
0.443 \\
1 \cdot 019\end{array}$ & $\begin{array}{c}-9 \cdot 9 \\
\star \\
25 \cdot 0 \\
-5 \cdot 8 \\
0 \cdot 75 \\
16 \cdot 9 \\
7 \cdot 7\end{array}$ \\
\hline
\end{tabular}

$\mathrm{CV}=$ coefficient of variation

* No value calculated because mathematically impossible.

†After adjusting to Gullstrand's normal eye.

Table 7 Repeated measurements of the volume above surface of elevations types 10 to 15 using the Heidelberg retina tomograph

\begin{tabular}{llllllllc}
\hline No & \multicolumn{2}{l}{$\begin{array}{l}\text { Volume above surface } \\
\left(\mathrm{mm}^{3}\right)\end{array}$} & & $\begin{array}{l}\text { Mean } \\
\left(\mathrm{mm}^{3}\right)\end{array}$ & $\begin{array}{l}\text { Real } \\
\left(\mathrm{mm}^{3}\right)\end{array}$ & $\begin{array}{l}S D \\
\left(\mathrm{~mm}^{3}\right)\end{array}$ & $\begin{array}{l}\mathrm{CV} \\
(\%)\end{array}$ & $\begin{array}{l}\text { Relative } \\
\text { error }(\%)\end{array}$ \\
\hline 10 & 2.33 & 2.3 & 2.388 & 2.339 & 2.304 & 0.045 & 1.912 & 1.534 \\
11 & 0.888 & 0.889 & 0.925 & 0.901 & 0.979 & 0.021 & 2.34 & -8 \\
12 & 1.49 & 1.594 & 1.486 & 1.523 & 1.536 & 0.061 & 4.02 & -0.82 \\
13 & 0.23 & 0.217 & 0.231 & 0.226 & 0.221 & 0.008 & 3.456 & $\begin{array}{r}2.262 \\
14\end{array}$ \\
15 & 1.067 & 1.125 & 1.132 & 1.108 & 1.115 & 0.036 & $\begin{array}{l}3.22 \\
-0.63\end{array}$ \\
\hline
\end{tabular}

$\mathrm{CV}=$ coefficient of variation

†After adjusting to Gullstrand's normal eye.
Reproducibility

The coefficient of variation of the parameter 'volume below contour' of three repeated measurements was in the range of $0.5 \%$ to $9.6 \%$ (mean $2.4 \%$ ) in the model eye (Table 5). In volunteers the coefficient of variation ranged from $3 \cdot 2 \%$ to $12 \cdot 3 \%$ with a mean of $6 \cdot 9 \%$ (Table 8).

The standard deviation of the parameter 'volume below surface' (Table 6) ranged from $0.4 \%$ to $22.6 \%$ (mean $4 \cdot 1 \%$ ) in the model eye. In volunteers it ranged from $2 \cdot 7 \%$ to $18 \cdot 1 \%$ with a mean of $6.9 \%$ (Table 9 ).

The coefficient of variation of the parameter 'volume above surface' (Table 7) ranged from $1.9 \%$ to $6 \cdot 1 \%$ with a mean of $3.5 \%$.

\section{COMPARISON OF THE ONHA AND THE HRT}

The standard deviations of HRT volume measurements were statistically significantly better than the standard deviations of ONHA volume measurements $(p=0.0277 / p=0.028$ : ONHA cup volume $v$ HRT volume below contour/surface).

In volunteers, the HRT volume measurements showed less variation than the ONHA volume measurements. This was statistically significant for the comparison of the ONHA cup volume with the HRT volume below surface $(p=$ 0.0267 ) but not statistically significant for the comparison of the ONHA cup volume with the HRT volume below contour $(p=0 \cdot 1327)$.

The accuracies of both instruments in measuring volumes did not differ $(p=0.6002$ : ONHA cup volume $v$ HRT volume below contour; $\mathrm{p}=$ 0.4631 : ONHA cup volume $v$ HRT volume below surface).

HRT and ONHA volumes differed by more than $20 \%$ in artificial papillae Nos 1,3 , and 7 . All of them are complex: Nos 1 and 7 are combinations of cones of different angles and No 3 (the cylinder) has vertical boundaries which may be difficult to register. It cannot be said which of the two machines performed better. In one of the above papillae the HRT was better, in another the ONHA.

In volunteers, the volumes of the two machines differed significantly in several cases (for example, Nos 1, 4, 5, 7) although the reproducibility of both instruments was comparable and reasonable in all these cases.

It cannot be said that both machines performed badly in the same volunteer. In case 11 the ONHA coefficient of variation was worse than the HRT coefficient of variation whereas in case 2 the ONHA performed as badly as the HRT.

\section{Discussion}

We used a model eye for the evaluation of the accuracy of the ONHA and the HRT. Our model eye differed from Gullstrand's model eye which made a mathematical adjustment necessary. Gullstrand's eye is not easy to build and many mistakes are possible when constructing such a delicate piece of optics. Therefore we thought it more apt to use an easy to construct model eye. Our results show that our model eye and mathe- 

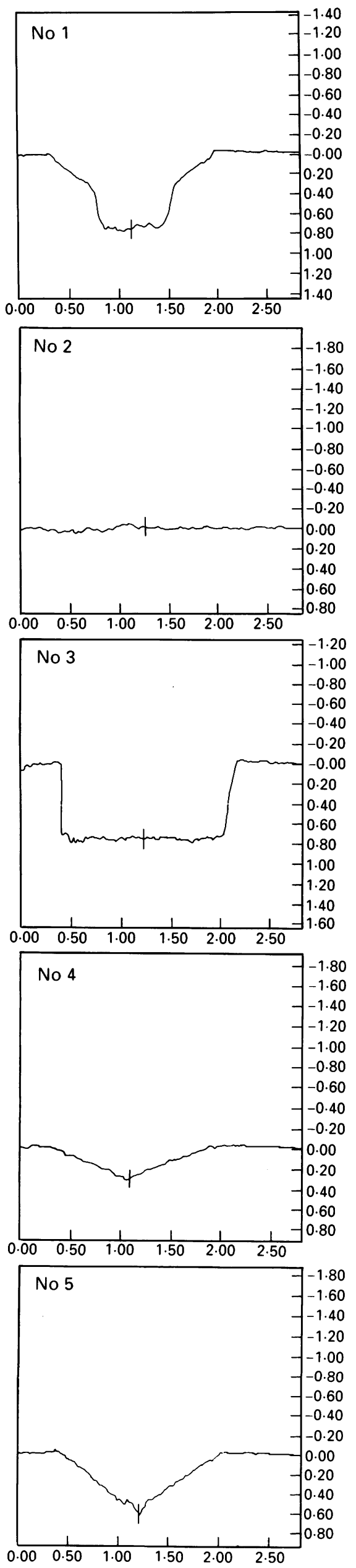
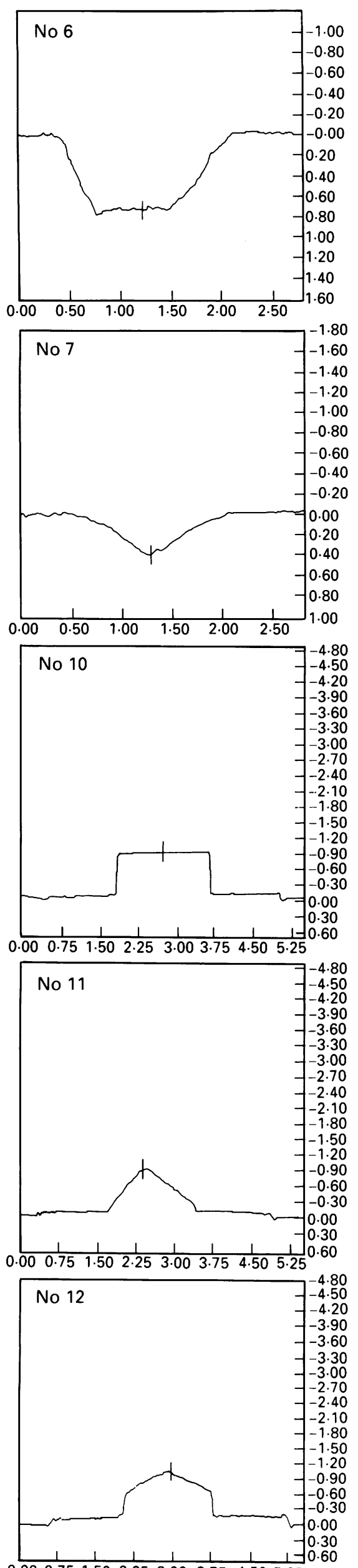
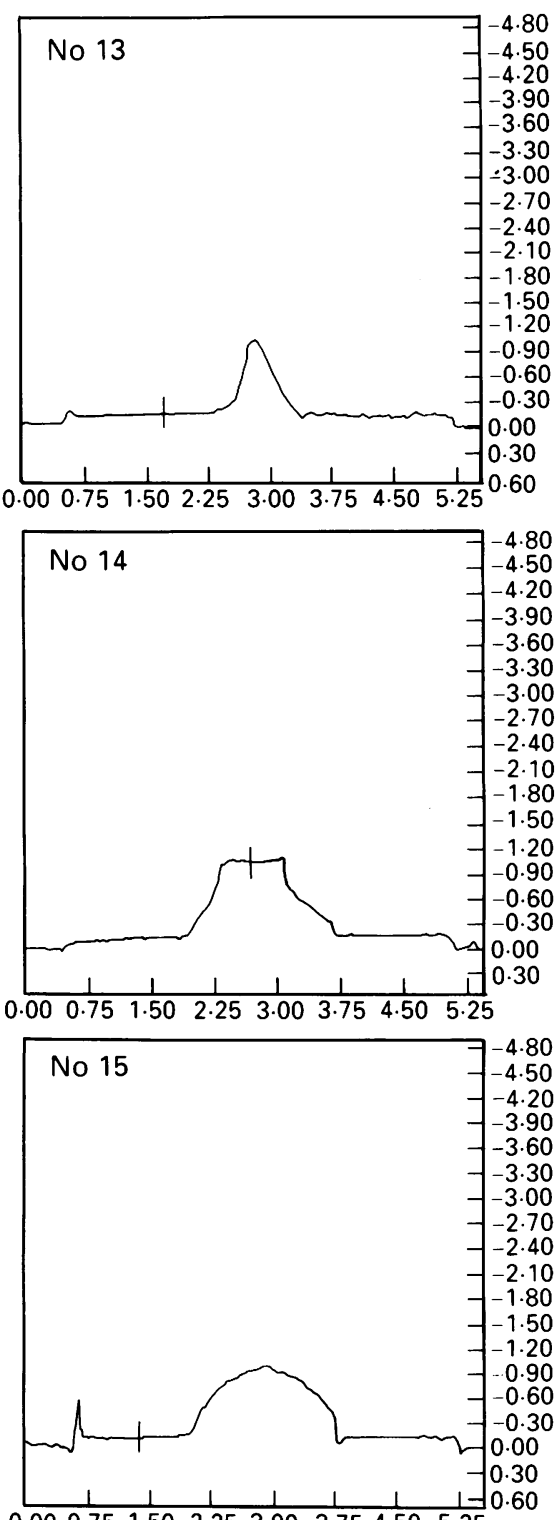

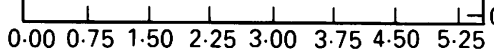

Figure 5 Profiles of the artificial papillae and elevations as they were registered by the Heidelberg retina tomograph. The numbers refer to the numbering in Figure 3. The scales are in $\mathrm{mm}$; the correct dimensions are obtained after mathematical correction to Gullstrand's eye. 
Table 8 Repeated measurements of the volume below contour in volunteers using the Heidelberg retina tomograph

\begin{tabular}{cllllllc}
\hline No & $\begin{array}{l}\text { Age } \\
\text { (years) }\end{array}$ & \multicolumn{2}{l}{$\begin{array}{l}\text { Volume below contour } \\
\left(\mathrm{mm}^{3}\right)\end{array}$} & $\begin{array}{l}\text { Mean } \\
\left(\mathrm{mm}^{3}\right)\end{array}$ & $\begin{array}{l}S D \\
\left(\mathrm{~mm}^{3}\right)\end{array}$ & $\begin{array}{l}\mathrm{CV} \\
(\%)\end{array}$ \\
\hline 1 & 40 & 0.363 & 0.437 & 0.432 & 0.411 & 0.041 & 10.07 \\
2 & 22 & 0.302 & 0.242 & 0.302 & 0.282 & 0.035 & 12.28 \\
3 & 25 & 0.397 & 0.346 & 0.398 & 0.38 & 0.03 & 7.819 \\
4 & 22 & 0.582 & 0.554 & 0.534 & 0.557 & 0.024 & 4.331 \\
5 & 22 & 0.117 & 0.11 & 0.094 & 0.107 & 0.012 & 11.02 \\
6 & 32 & 0.341 & 0.338 & 0.306 & 0.328 & 0.019 & 5.908 \\
7 & 30 & 0.295 & 0.323 & 0.309 & 0.309 & 0.014 & 4.531 \\
8 & 27 & 0.104 & 0.107 & 0.1 & 0.104 & 0.004 & 3.388 \\
9 & 30 & 0.948 & 0.908 & 0.973 & 0.943 & 0.033 & 3.477 \\
10 & 30 & 0.348 & 0.314 & 0.301 & 0.321 & 0.024 & 7.561 \\
11 & 29 & 0.069 & 0.083 & 0.072 & 0.075 & 0.007 & 9.872 \\
12 & 22 & 0.299 & 0.258 & 0.314 & 0.29 & 0.029 & 9.985 \\
13 & 30 & 0.384 & 0.409 & 0.395 & 0.396 & 0.013 & 3.164 \\
14 & 35 & 0.275 & 0.262 & 0.246 & 0.261 & 0.015 & 5.565 \\
15 & 26 & 0.141 & 0.149 & 0.153 & 0.148 & 0.006 & 4.138 \\
\hline
\end{tabular}

$\mathrm{CV}=$ coefficient of variation.

Table 9 Repeated measurements of the volume below surface in volunteers using the Heidelberg retina tomograph

\begin{tabular}{|c|c|c|c|c|c|c|c|}
\hline \multirow{3}{*}{$\frac{N o}{1}$} & \multirow{3}{*}{$\begin{array}{l}\begin{array}{l}\text { Age } \\
\text { (years) }\end{array} \\
40 \\
22\end{array}$} & \multicolumn{3}{|c|}{$\begin{array}{l}\text { Volume below surface } \\
\left(\mathrm{mm}^{3}\right)\end{array}$} & \multirow{2}{*}{$\begin{array}{c}\begin{array}{c}\text { Mean } \\
\left(\mathrm{mm}^{3}\right)\end{array} \\
0.323\end{array}$} & \multirow{2}{*}{$\begin{array}{l}\begin{array}{l}S D \\
\left(\mathrm{~mm}^{3}\right)\end{array} \\
0.016\end{array}$} & \multirow{2}{*}{$\frac{\begin{array}{l}C V \\
(\%)\end{array}}{4.915}$} \\
\hline & & 0.305 & 0.329 & 0.335 & & & \\
\hline & & 0.219 & $0 \cdot 168$ & $0 \cdot 242$ & 0.21 & 0.038 & 18.06 \\
\hline 3 & 25 & 0.293 & 0.271 & 0.319 & 0.294 & 0.024 & $8 \cdot 163$ \\
\hline 4 & 22 & 0.417 & 0.436 & 0.416 & 0.423 & 0.011 & 2.664 \\
\hline 5 & 22 & 0.045 & 0.045 & 0.042 & 0.044 & 0.002 & 3.936 \\
\hline 6 & 32 & $0 \cdot 242$ & 0.244 & 0.22 & 0.235 & 0.013 & $5 \cdot 659$ \\
\hline 7 & 30 & $0 \cdot 264$ & 0.28 & 0.263 & 0.269 & 0.01 & 3.546 \\
\hline 8 & 27 & 0.038 & 0.043 & 0.034 & 0.038 & 0.005 & $11 \cdot 76$ \\
\hline 9 & 30 & 0.834 & 0.807 & 0.891 & 0.844 & 0.043 & 5.081 \\
\hline 10 & 30 & 0.277 & 0.264 & 0.24 & 0.26 & 0.019 & $7 \cdot 21$ \\
\hline 11 & 29 & 0.031 & 0.034 & 0.028 & 0.031 & 0.003 & $9 \cdot 677$ \\
\hline 12 & 22 & 0.227 & 0.198 & 0.212 & 0.212 & $0 \cdot 015$ & 6.83 \\
\hline 13 & 30 & 0.337 & 0.373 & 0.338 & 0.349 & 0.021 & $5 \cdot 869$ \\
\hline 14 & 35 & 0.215 & 0.208 & 0.204 & $0 \cdot 209$ & 0.006 & $2 \cdot 664$ \\
\hline 15 & 26 & $0 \cdot 107$ & $0 \cdot 113$ & 0.125 & 0.115 & 0.009 & $7 \cdot 97$ \\
\hline
\end{tabular}

matical adjustments to Gullstrand's eye did not cause too much bias. About half the measured ONHA area and volume values and HRT volume values were above or below the real value so that there was no systematical error. The real volume of artificial papilla No 5 was twice the volume of artificial papilla No 4 , and the volume of artificial papilla No 6 was twice the volume of artificial papilla No 5 . The relative volumes of the three artificial papillae were measured correctly by the HRT and the ONHA so that our mathematical model did not cause distortions. Thus, we are convinced that the model eye and the adjustments to Gullstrand's normal eye were a useful approximation.

The accuracy of the ONHA was analysed by Shields. ${ }^{6}$ Shields ${ }^{6}$ found the accuracy of the ONHA to be between 5 and $11 \%$ for the parameter 'cup diameter'. Although he used a model eye that differed considerably from ours the accuracy (for the two dimensional parameter 'cup area') we found was comparable with his data.

There are no detailed reports about the accuracy of the HRT yet, although Weinreb and Dreher ${ }^{91+}$ provide some data for the laser scanning tomograph, the predecessor of the HRT. Weinreb ${ }^{9}$ measured an accuracy of 0.3 to $3 \cdot 1 \%$ for the one dimensional parameter 'cup diameter' in a phakic model eye. Dreher ${ }^{14}$ found the accuracy to be $2 \cdot 0 \%$ for areas and $11.7 \%$ for depth measurements. He did not mention any accuracies for the most interesting parameter 'volume below contour (surface)'. So, our $11 \cdot 3 \%$
(11.0\%) accuracy for the latter parameter is not directly comparable with his data. However, if we use his $2 \cdot 0 \%$ accuracy for areas and the $11 \cdot 7 \%$ accuracy for depth measurements for calculating $V\left(2^{2}+11 \cdot 7^{2}\right)$, the resulting $11.9 \%$ is comparable with our data (compare Sachs ${ }^{15}$ ).

The HRT performed poorly on the flat surface registering a volume erroneously. The reason for this may be that the contour line was tilted with regard to the flat surface. Therefore the algorithm which is used to calculate the volume below contour (surface) and has to interpolate between two stacked focal planes outputs a wedge-shaped volume between two focal planes. The 'volume' of the flat surface was about 0.03 $\mathrm{mm}^{3}$, about $10 \%$ of the mean volume of the papillae in our volunteers. The mistake is therefore relevant only in discs with a flat excavation (for example, volunteer No 8). The latest release of the HRT software makes up for the tilt and perhaps the mistake is even less with this updated software.

The volumes of the artificial papillae or of the volunteers differed from ONHA to HRT in individual cases (for example, artificial papilla Nos $1,3,7$; volunteers $1,4,5,7$ ). We could not find any systematic reason why one machine performed better in the same artificial papilla or volunteer. Complex geometries of the artificial papillae may contribute to the differences in performance but this is a hypothesis. The difference may as well be caused by chance.

ONHA and HRT deliver different parameters of the papilla. The ONHA provides us with two dimensional parameters such as the 'cup area' but calculates the three dimensional parameter 'cup volume', too. The ONHA 'cup volume', however, is usually not used for clinical purposes. The reason is that the definition of the upper boundary that is necessary for the calculation of a volume is one by three points outside the papilla. So, comparing cup volumes from one examination to the next becomes inaccurate as the reference plane may have shifted by a decrease in the thickness of the retinal nerve fibre layer. For the purpose of directly comparing ONHA and HRT we used the parameter 'cup volume', thereby avoiding the comparison of parameters of different geometrical dimension.

The relative error of the HRT was worse than the relative error of the ONHA. The difference, however, was not statistically significant in measuring volumes.

The most often used parameters of the ONHA are two dimensional ones whereas the HRT provides us with three dimensional parameters. Both machines allege the usefulness of their parameters in the follow up of glaucoma. Therefore, it would be interesting to compare the most often used parameters of the two machines although the comparison of a two dimensional parameter with a three dimensional one is questionable. A mathematical correction may overcome this problem. If we assume that the error is the same in each geometrical dimension, then we can multiply the relative error of the ONHA 'cup area' of $6.6 \%$ by $3 / 2$ which yields $9 \cdot 9 \%$. This compares favourably with the $10-$ $11 \%$ relative error of the HRT. So, the three dimensional volume parameters of the HRT are 
measured as exactly as the two dimensional area parameters of the ONHA. The three dimensional parameters of the HRT are, however, clinically useful. If the scleral ring is used no shift of the reference plane should occur even if the nerve fibre layer is reduced.

Glaucomatous cupping is a combination of an increasing cup area and cup depth. Therefore, the three dimensional cup volume which is provided by the HRT with an accuracy identical to the accuracy of the ONHA is perhaps more apt to detect subtle changes in the progression of glaucoma than the parameter 'cup area' of the ONHA.

We repeated each measurement three times to calculate the standard deviation. Rohrschneider ${ }^{16}$ calculated the standard deviation of three and five repeated measurements and did not find any significant difference. These data and those of Weinreb and Lusky ${ }^{8118}$ confirm our opinion that three measurements are sufficient for the calculation of the standard deviation and therefore the reproducibility.

The reproducibility of our ONHA measurements in the model eye and in volunteers was in the range of other published reports. ${ }^{1-5719}$ Tomita $^{20}$ found a reproducibility of the HRT of about $10 \%$ for the cup volume comparable with other data. Dreher ${ }^{21}$ and Lusky ${ }^{22}$ provide data for one dimensional parameters which cannot be compared with our data. The latter is true of von der Lippe's data for areas, too. ${ }^{23}$ Von der Lippe provides us with data which permit us to calculate the coefficient of variation. After mathematical adjustment ${ }^{15}$ his coefficient of variation is $\mathbf{9 . 9 \%}$ for three dimensional parameters which is comparable with our $6.9 \%$ in measurements with the HRT.

In volunteers our reproducibility (HRT) was in the range of other published reports ${ }^{101124}$ (Kruse and Rohrschneider ${ }^{10}$ used the predecessor of the HRT). It was, however, worse than in the model eye. This is not surprising since the optical irregularities of the human eye surpass those in a model eye. Such optical irregularities cause scattering and reflection of incoming light that disturbs the calculation of the cup area and the volume below surface (contour). So, the reproducibility in the model eye is superior to the reproducibility in volunteers.

The reproducibility of the HRT in volunteers is reasonably good and superior to the ONHA reproducibility.

The HRT provides two parameters: 'volume below surface' and 'volume below contour'. The operation manual of the HRT alleges that the first one is superior to the second one as it compensates for slight variations in the inevitable tilt of the camera versus the optical axis of the eye. In our study we found both parameters equally useful for characterising volumes.

The HRT differs in one essential ability from the ONHA: it is programmed to measure elevations. Accuracy and reproducibility in doing so were very good in our study. There are no reports about the performance of the HRT in measuring elevations yet, So, our results cannot be compared with the literature.

In our opinion the HRT is a useful tool for the management of glaucoma patients. Its 'volume below contour (surface)' reflects the real cup volume with sufficient reproducibility and accuracy. The 'volume above surface' quantifies accurately fundus elevations.

Furthermore the HRT is much speedier than the ONHA in image acquisition and analysis owing to faster software and hardware. In our experience it is, furthermore, unnecessary to dilate the patient's pupil for image acquisition with the HRT whereas it is necessary to dilate the pupils for measurements with the ONHA. Recently, the HRT has been shown to be able to be used for image analysis even in patients with cataract. ${ }^{25}$ This is not possible with the ONHA. Furthermore, the HRT is able to quantify elevations, which also is not possible with the (no longer produced) ONHA.

The introduction of the HRT should been seen as significant progress when compared with the ONHA in the quantification of glaucomatous cupping and fundus elevations, and it is an easy to use and reliable machine.

1 Bishop KI, Werner EB, Krupin T, Kozart DM, Beck SR, Nunan FA, et al. Variability and reproducibility of optic disk topographic measurements with the Rodenstock optic nerve head analyzer. Am f Ophthalmol 1988; 106: 696-702.

2 Caprioli J, Klingbeil U, Sears M, Pope B. Reproducibility of optic disk measurements with computerized analysis of
stereoscopic video images. Arch Ophthalmol 1986; 104: stereosco $1035-9$.

3 Funk J, Steeb R. Verbesserte Reproduzierbarkeit der computergesteuerten Papillenstrukturanalyse. Klin Monatsbl Augenheilkd 1991; 199: 25-9.

4 Mikelberg FS, Douglas GR, Schulzer M, Cornsweet TN, Wijsman K. Reliability of optic disk topographic measurements recorded with a video-ophthalmograph. Am $\mathcal{f}$ Ophthalmol 1984; 98: 98-102.

5 Shields MB, Martone JF, Shelton AR, Ollie AR, MacMillan J. Reproducibility of topographic measurements with the optic nerve head analyzer. Am f Ophthalmol 1987; 104: 581-6.

6 Shields MB, Tiedeman JS, Miller KN, Hickingbotham D, Ollie AR. Accuracy of topographic measurements with the optic nerve head analyzer. Am $\mathcal{F}$ Ophthalmol 1989; 107: 273-9.

7 Siebert M, Gramer E, Leydhecker W. Die Reproduzierbarkeit der Papillenmeßwerte bei der Untersuchung mit dem Optic Nerve Head Analyzer. Spektrum Augenheilkd 1988; 2/4: 16776.

8 Weinreb RN, Lusky M, Bartsch D-U, Morsman D. Effect of repetitive imaging on topographic measurements of the optic nerve head. Arch Ophthalmol 1993; 111: 636-8.

9 Weinreb RN, Dreher AW. Reproducibility and accuracy of topographic measurements of the optic nerve head with the laser tomographic scanner. In: Nasemann JE, Burk ROW, laser tomographic scanner. In: Nasemann JE, Burk ROW,
eds. Scanning laser ophthalmoscopy and tomography. München: Quintessenz, 1990.

10 Kruse FE, Burk ROW, Völcker H-E, Zinser G, Harbarth U. Reproducibility of topographic measurements of the optic nerve head with laser tomographic scanning. Ophthalmology 1989; 96: 1320-4.

11 Rohrschneider K, Burk ROW, Völcker HE. Reproducibility of topometric data acquisition in normal and glaucomatous optic nerve heads with the laser tomographic scanner. Graefes Arch Clin Exp Ophthalmol 1993; 231: 457-64.

12 Gramer E, Klingbeil U. Quantitative disc analysis with the optic nerve head analyzer. Z Prakt Augenheilkd 1986; 7: 30 .

13 Klingbeil U. Fundus geometry measured with the analyzing stereo video ophthalmoscope. In: Masters BR, ed. stereo video ophthalmoscope. In: Masters BR, ed.
Noninvasive diagnostic techniques in ophthalmology. Berlin,
Heidelberg, New York: Springer, 1990.

14 Dreher AW, Weinreb RN. Accuracy of topographic measurements in a model eye with the laser tomographic scanner. Invest Ophthalmol Vis Sci 1991; 32: 2992-6.

15 Sachs L. Angewandte Statistik. 6. Auflage. Berlin, Heidelberg, New York, Tokyo: Springer, 1984: 78.

16 Rohrschneider K, Burk ROW, Völcker HE. Vergleich von zwei Laser-Scanning-Tomographie-Systemen zur dreidim-

ensionalen Papillenanalyse. Ophthalmologe 1993; 90: 613-9.
7 Lusky M, Morsman D, Bartsch D-U, Weinreb RN. Effect of repetitive imaging D, Bartsch D-U, Weinreb RN. Effect of repetitive imaging on topographic measurements of the optic

18 Lusky M, Morsman D, Bartsch D-U, Weinreb RN. Repetitive imaging in confocal scanning laser tomography. Repetitive imaging in confocal scanning laser tomography.
4th International Meeting on Scanning Laser Ophthalmoscopy, Tomography and Microscopy, Heidelberg, 19-21 May 1993.

19 Dannheim F, Klingbeil U. Die Bestimmung räumlicher Papillendaten mit dem 'Fundusanalysator'. Fortschr Ophthalmol 1986; 83: 527-9.

20 Tomita G, Honbe K, Kitazawa Y. Reproducibility of optic disc measurements with the Heidelberg Retina Tomograph in eyes before and after pilocarpine instillation. 4th 
International Meeting on Scanning Laser Ophthalmoscopy, Tomography and Microscopy, Heidelberg, 19-21 May 1993.

21 Dreher AW, Tso PC, Weinreb RN. Reproducibility of topographic measurements of the normal and glaucomatous optic nerve head with the laser tomographic scanner. $A m \mathcal{F}$ Ophthalmol 1991; 111: 221-9.

22 Lusky M, Taylor J, Bosen ME, Weinreb RN. Reproducibility of topographic measurements of the optic nerve head with the retina tomograph. Invest Ophthalmol Vis Sci 1992; 33 (suppl): 885
23 Lippe von der I, Martus P, Naumann GOH. Laser scanning tomography and morphometry: comparison of two methods for optic disc size and excavation measurements. Invest Ophthalmol Vis Sci 1993; 34 (suppl): 1506.

24 Shafranov G, Schumer RA, Lustgarten JS, Podos SM Variability of optic nerve head parameters using the Heidelberg retinal tomograph. Invest Ophthalmol Vis $\mathrm{Sc}$ 1993; 34 (suppl): 1507.

25 Thiel A, Bräuning J, Frohn A. Cup volume measurements by confocal or stereoparallactical means? Invest Ophthalmol Vis Sci 1993; 34 (suppl): 1506. 